\title{
Surveillance system of severe influenza cases admitted to the regional ICU,2009-2015
}

\section{Esra Morvan*, Joanna Parra, Gerard Roy and Dominique Jeannel}

Regional office, Sante publique France, Orléans, France

\section{Objective}

The study aimed at: i) analyses the regional characteristics and risk factors of severe influenza, taking into account dominant circulating virus(es) ii) estimate the regional completeness of the surveillance system.

\section{Introduction}

Every year, circulating influenza viruses generate a significant number of deaths. During the 2009 pandemic influenza A(H1N1), a national non mandatory surveillance system of severe influenza cases admitted to intensive care units(ICU) was set up in France. This surveillance is regionally driven by the regional offices (CIRE) of Santé publique France, the French Public Health Agency. This report provides epidemiologic analysis of the recorded data since the implementation of surveillance in the Centre-Val de Loire region over seasons 2009-10 to 2015-16 in regard of influenza epidemics dynamics.

\section{Methods}

Surveillance was carried out each year from October to April. Descriptive and analytic analyses were conducted to compare population characteristics, pre-existing risk factors and the clinical data according to influenza season and dominant circulating influenza virus(es). Logistic regressions were performed to identify factors associated with an increased risk of acute respiratory distress syndrome (ARDS) or death. Two capture-recapture analyses were performed to establish the completeness of the surveillance system in the region. The first one was realized on all cases, using two data sources (hospital records/surveillance data) and the second one, only on deaths, using three data sources(additional source: medical death certificates).

\section{Results}

From 2009-10 to 2015-16, the outbreak of influenza epidemics was started more and more late. The number of severe influenza cases reported in the Loire Valley varied from 19 in 2010-11 to 75 in 2014-15. Overall, the most affected population was adults, from $41 \%$ in $2011-12$ to $83 \%$ in $2009-10$. However seniors (more than 65 years old) represented an important part of patients during three epidemics: $50 \%$ in $2011-12$ and around $45 \%$ during the two last seasons; during these epidemics, men, (60\%-68\%), were more affected than women. Patients' pre-existing risk factors were mainly: being older than 65 years old and suffering of cardiac or pulmonary diseases. The comparison by dominant viruses over the seasons revealed that when $\mathrm{A}(\mathrm{H} 1 \mathrm{~N} 1)$ virus prevailed, severe influenza occurred mainly in adults patients with any type of pre-existing risk factors whereas when $\mathrm{A}(\mathrm{H} 3 \mathrm{~N} 2)$ virus prevailed, seniors with pre-existing pulmonary disease were the most affected. More than a third of patients declared an ARDS. The overall observed lethality was close to $16 \%$. ARDS occurred more frequently in patients who were middle-aged (45-64 years), immunocompromised or infected with $\mathrm{A}(\mathrm{H} 1 \mathrm{~N} 1)$. Pre-existing pulmonary disease was a protective factor. Risk factors associated with death were being older than 65 years, male and having declared an ARDS. The completeness of this surveillance system was estimated by capture-recapture methods at $59 \%$ for severe influenza cases and $40 \%$ for death cases.

\section{Conclusions}

The epidemiology of severe influenza and epidemics dynamics in the Centre-Val de Loire follow the national trends. Every season is characterized by the same dominant virus at national and regional levels in intensive care units. Influenza epidemics 2009-10 and 2014-15 were particularly long and severe, the first dominated by the $\mathrm{A}(\mathrm{H} 1 \mathrm{~N} 1) \mathrm{pdm} 09$ virus and the second by the $\mathrm{A}(\mathrm{H} 3 \mathrm{~N} 2)$. Our study has demonstrated that the populations at risk of severe influenza differ according to the circulating virus(es). According to the obtained estimations, the completeness of the surveillance system, based on voluntary report by physicians, can be considered as satisfactory. Regarding influenza deaths relatively low percentage of completeness may be explained by the fact that two sources are hospital based whereas the third one, medical death certificates, includes all influenzadeaths with no information on the death place. Many patients were not vaccinated or their status was unknown. Most cases admitted to ICU presented pre-existing risk factors included in eligibility criteria in influenza vaccination policies. This study outlines the importance of vaccination as the first prevention measure.

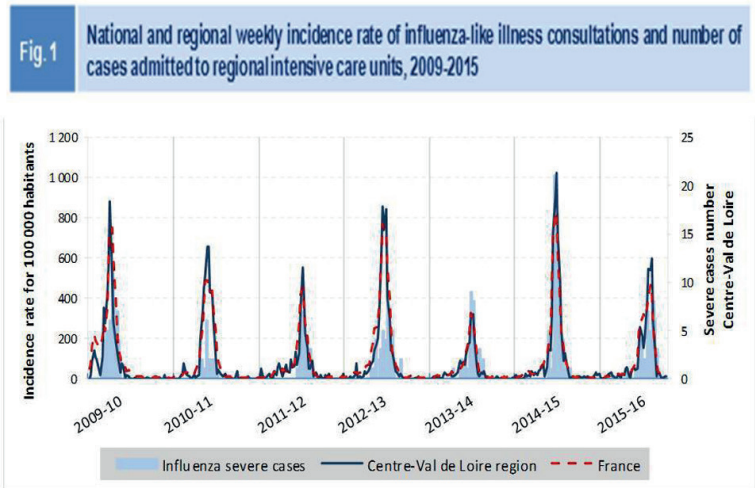

Keywords

severe influenza; surveillance; risk factors; completeness; Centre-Val de Loire

\section{Acknowledgments}

To Md Isabelle Runge (Orléans Regional hospital), Md Denis Garot, Md Thierry Perez (Tours university hospital) data providers

\section{References}

1.Hubert B, Loury P, Ollivier R. Les hospitalisations pour grippe en service de réanimation dans la région des Pays-de-la-Loire (France), 2006-2011. Numéro thématique. Surveillance de la grippe, saison 2010-2011 : bilan après la pandémie. Bull Epidemiol Hebd 2011; 37-38:401-4.

2.Berger F, Parent du Châtelet I, Bernillon P et Gallay A. Surveillance des infections invasives à méningocoque en France métropolitaine en 2005 - Évaluation quantitative par la méthode de capture-recapture à trois sources. Saint-Maurice (Fra) : Institut de veille sanitaire, août 2010, 43 p. Disponible sur : www.invs.sante.fr

\section{*esra morvan}

E-mail: esra.morvan@ars.sante.fr 